\title{
Teoria polifônica da enunciação: claro enigma
} Political theory of enunciation: clear enigma

\author{
Andréia Inês Hanel Cerezoli ${ }^{1}$ \\ Carla Roberta Sasset ${ }^{2}$
}

Universidade de Caxias do Sul, Programa de Pós-Graduação em Letras, Programa de Pós-Graduação em Educação. Caxias do Sul, RS, Brasil

Mestre em Letras - Estudos linguísticos pela Universidade de Passo Fundo (UPF). Doutoranda em Letras na Universidade de Caxias do Sul (UCS). E-mail: andreia orgerezoli:0002-8563-1826

do Sul (UCS), Doutoranda emidade de Caxias Universidade de Caxias do Sul (UCS). (Di) https://orcid.org/0000-0001-7609-1330 E-mail: crsasset@ig.com.br
RESUMO: As dificuldades de leitura estão cada vez mais evidentes nas diferentes avaliações censitárias. Assim, a escola anseia por estratégias de leitura que permitam modificar o atual quadro de competências de leitura. O objetivo deste trabalho é apresentar os diferentes níveis envolvidos num processo de leitura, via perspectiva enunciativa, e analisar uma proposta de trabalho de compreensão leitora a partir da perspectiva da Semântica Argumentativa, mais pontualmente, a partir dos postulados da Teoria Polifônica da Enunciação. A base teórica adotada envolve documentos elaborados e divulgados pelo Ministério da Educação (MEC) e pelo Instituto Nacional de Estudos e Pesquisas Educacionais Anísio Teixeira (INEP), além de autores como Ducrot, Barbisan e Azevedo. Na análise realizada, pode-se perceber o predomínio de questões que valorizam aspectos extratextuais, impossibilitando, ou reduzindo as condições de compreensão leitora. Conclui-se, assim, que embora a leitura esteja no centro de muitas discussões acerca do desempenho dos alunos, poucas são as atividades propostas para que o aluno possa desenvolver a habilidade de reconstituição dos sentidos já existentes no discurso via materialidade linguística.

Palavras-chave: Semântica argumentativa; Teoria Polifônica da Enunciação; Compreensão leitora.

ABSTRACT: The difficulties of reading are increasingly evident in the different census evaluations. Thus, the school yearns for reading strategies that allow to modify the current framework of reading skills. The objective of this work is to present the different levels involved in a reading process, through enunciative perspective, and to analyze a proposal of reading comprehension work from the perspective of Argumentative Semantics, more punctually, from the postulates of the Polyphonic Theory of Enunciation. The theoretical basis adopted involves documents prepared and disseminated by the Ministry of Education (MEC) and the National Institute of Studies and Educational Research Anísio Teixeira (INEP), as well as authors such as Ducrot, Barbisan and Azevedo. In the analysis performed, one can perceive the predominance of questions that value extratextual aspects, making it impossible or reducing the conditions of reading comprehension. It is concluded, therefore, that although the reading is at the center of many discussions about the performance of the students, few are the activities proposed so that the student can develop the capacity of reconstitution of the existing senses in the discourse via linguistic materiality.

Keywords: Argumentative semantics; Polyphonic Theory of Enunciation; Reading comprehension. 


\section{Introdução}

título atribuído a este artigo Claro enigma é a paráfrase de uma obra de Carlos Drummond de Andrade. Muito provocador, tem a grandeza de combinar dois signos (para lembrar Saussure) que mereceriam por si só toda a descrição do artigo, mas o propósito de parafrasear Drummond, concentra-se na maneira como a Teoria da Polifonia ainda é compreendida nos estudos linguísticos. Há muito tempo, a grande maioria dos linguistas (semanticistas) concorda com a máxima da Teoria da Polifonia de que em um enunciado estão presentes várias vozes, o que remete ao adjetivo "Claro" proposto no título deste artigo, porém, mesmo com o reconhecimento dessas diferentes vozes, poucos são os trabalhos acadêmicos voltados a mostrar como essas diferentes vozes constituem o sentido nos enunciados, o que se apresenta como o "Enigma” apontado no título.

Assim, considerando a Teoria da Polifonia de Oswald Ducrot como aporte teórico dessa pesquisa, o objetivo deste trabalho será apresentar uma proposta de compreensão leitora a partir dos pressupostos teóricos desenvolvidos pelo semanticista. Selecionou-se a compreensão leitora, por se acreditar que as dificuldades de compreensão leitora precisam ser encaradas com muita atenção pelos linguistas, pois compartilhando os pressupostos apresentados por Azevedo (2016, p. 49) de que o linguista transforma o sistema linguístico em objeto de estudo, lançando um olhar epistemológico, teórico e metodológico para descrever e explicar tal sistema, sua constituição e atualização como fenômeno social e individual, o linguista deve, então, propor teorias que para que o usuário da língua (aluno ou não) faça da língua um instrumento para conferir sentido às suas interações verbais. E, sendo a compreensão leitora de extrema importância para que o usuário possa conferir sentido a muitas de suas interações verbais diárias e uma das grandes dificuldades apresentadas hoje, cabe ao linguista essa pauta.
Já a Teoria Polifônica foi eleita a base teórica para a análise que será aqui apresentada por dois pressupostos teóricos. Primeiramente, por ser uma teoria que se filia aos estudos imanentistas de Saussure, ou seja, o que importa para a descrição do sentido é apenas o material linguístico do discurso, sendo o material extratextual totalmente dispensável para a reconstituição do sentido do discurso. O segundo pressuposto é o de que em um enunciado qualquer estão presentes vários pontos de vistas, várias vozes constituindo seu sentido. Assim, este trabalho justifica-se por apresentar uma proposta de compreensão leitora, a partir de uma perspectiva enunciativa, voltada para a materialidade linguística comum a todos os usuários da língua.

Para uma melhor visualização do trabalho, o mesmo estará organizado em três grandes seções: a primeira estará voltada para a questão da leitura, principalmente nas diretrizes apresentadas nos Parâmetros Curriculares Nacionais (PCNs) e nas orientações da Prova Brasil, fonte do discurso selecionado para a análise. A segunda seção tem como proposta apresentar os postulados teóricos assumidos na análise. E, a última seção, traz a proposta de compreensão leitora apresentada pela Prova Brasil e, em seguida, a proposta aqui elaborada de compreensão leitora, via Teoria Polifônica.

\section{Parâmetros Curriculares Nacionais: a questão da leitura}

Algumas questões são extremamente desafiadoras aos educadores hoje. Uma das maiores inquietudes, já há algum tempo, certamente circula acerca das questões de leitura na escola. Teixeira (2005, p. 195) já alerta que "Antes de [...] entrar nessa discussão, é preciso considerar que a leitura é um fenômeno complexo que não se esgota em um só modo de olhar." Assim, retomando o mestre de Genebra e sua célebre frase "[...] é o ponto 
de vista cria o objeto [...]"( SAUSSURE, 2006, p. 15) afirma-se que o ponto de vista assumido para a definição do objeto leitura serão os postulados da Semântica Argumentativa.

Os Parâmetros Curriculares Nacionais (PCNs) (1 a 4 séries) - Língua Portuguesa - foram divulgados pelo Ministério da Educação (MEC) em 1997 e, embora, tenham sido elaborados com o propósito de servir como referencial para o trabalho do professor, sabe-se que também passaram a servir como "modelo" a ser seguido, talvez por apresentarem os objetivos que os alunos devem demonstrar ao final do ensino fundamental e, até mesmo, em cada uma de suas etapas, ou por servirem como base para a elaboração das avaliações em larga escala aplicadas no Brasil.

Segundo o Referencial, o documento surge após a constatação de que o fracasso escolar está diretamente relacionado às habilidades de leitura e escrita. Logo, a área de Língua Portuguesa aparece diretamente ligada à progressão nos estudos, à participação ativa na sociedade e a muitos outros aspectos individuais e sociais.

O material ainda mostra que os conteúdos de Língua Portuguesa caracterizam-se, de forma geral, em: Língua oral: usos e formas; Língua escrita: usos e formas e Análise e reflexão sobre a língua. O bloco de conteúdos Língua escrita: usos e formas, subdivide-se em: Prática de leitura e Prática de Produção de Textos. Neste trabalho, pelo foco adotado, a partir de agora será considerado o eixo da Prática de leitura. No entanto, antes de iniciar a descrição das concepções de leitura presentes no Referencial, cabem duas observações extremamente pertinentes para esta pesquisa e presentes naquele material. $\mathrm{O}$ primeiro ponto que merece destaque é "Parte-se da concepção de que determinados objetivos só podem ser conquistados se os conteúdos tiverem um tratamento didático específico [...]" (BRASIL, 1997, p. 37) ou seja, a leitura, como conteúdo, precisa ser objeto de reflexão didática, abandonando-se a crença de que as habilidades de leitura "apareceriam" por força de repetição, ou por passe de mágica nos alunos. O segundo ponto, intimamente relacionado com o primeiro, reafirma a importância do professor no desenvolvimento da aprendizagem “[...] a intervenção pedagógica do professor tem valor decisivo no processo de aprendizagem [...]" (BRASIL, 1997, p. 38). Azevedo (2016a, p. 50) é mais precisa quando, ao definir a função do professor de língua afirma “[...] o professor de língua tem por profissão auxiliar no processo de qualificação e aprimoramento dos diferentes usos linguísticos que seus estudantes fazem e poderão vir a fazer."

Quanto à prática de leitura, propriamente, o Referencial afirma "O trabalho com leitura tem como finalidade a formação de leitores competentes e, consequentemente, a formação de escritores [...]" (BRASIL, 1997, p. 30). Vê-se aqui uma visão da leitura como meio para algo e não como atividade fim, ou seja, o aluno deve ler para algo além da própria leitura. Azevedo (2016a) também discute esse "dogma" muitas vezes reproduzido por professores aos seus alunos. No entanto, a autora aponta que as habilidades de escrita não são apenas decorrentes da quantidade das leituras realizadas, mas da qualidade das leituras realizadas. É preciso que o aluno aprenda a ler além daquilo que o locutor disse, mas, também, como disse, quais as combinações que elaborou, quais as associações são possíveis a partir daquelas combinações do discurso. Azevedo (2016a, p. 56) sugere, que, assim, “[...] o leitor possa transferir as estratégias percebidas na leitura para a sua própria produção.” Ora, para o aluno aprender a realizar esse processo de leitura, o professor precisa orientá-lo, eis que surge a Teoria da Polifonia, de Oswald Ducrot, que será apresentada na sequência, para fundamentar o trabalho pedagógico do professor.

Na sequência, na tentativa de descrever a leitura o Referencial afirma 
A leitura é um processo no qual o leitor realiza um trabalho ativo de construção do significado do texto, a partir dos seus objetivos, do seu conhecimento sobre o assunto [...] Trata-se de uma atividade que implica, necessariamente, compreensão na qual os sentidos começam a ser construídos antes da leitura propriamente dita (BRASIL, 1997, p. 41).

Tal qual descrita aqui, a leitura não é caracterizada pelo seu material linguístico, mas, principalmente, pelos conhecimentos que a precedem. A partir dessa concepção de leitura, aqueles alunos que não têm conhecimento prévio sobre o assunto, ou seu autor, ou suas características, já estão "sentenciados" a não ler. Teixeira (2005) mostra que concepções como essa estão muito vinculadas a teorias psicológicas de orientação cognitivista, quando o leitor utiliza seus conhecimentos prévios (linguístico, textual, enciclopédico) ativados no processo de leitura para tentar, então, compreender o conhecimento do produtor do texto.

Na sequência do próprio texto do referencial, mais uma passagem intrigante "Um leitor competente é alguém que, por iniciativa própria, é capaz de selecionar, dentre os textos que circulam socialmente, aqueles que podem atender a uma necessidade sua." (BRASIL, 1997, p. 41). Partindo-se dessa concepção de competência, o leitor lê apenas aquilo que possa atender uma necessidade imediata, não aqueles textos que lhe são solicitados ou com os quais vai se deparar ao longo da vida. Azevedo (2016b, p. 73) concebe a leitura competente como "[...] aquela capaz de compreender o jogo "polifônico" que constitui o sentido do discurso." e compreende a leitura como fator fundamental para o exercício da cidadania, ultrapassando a realidade escolar do aprendiz.

Veja-se que o documento do MEC que serve como parâmetro para as aulas de leitura é muito impreciso quanto ao 0 que é ler? O que é leitura? O que é leitura competente? Tais imprecisões são muito sérias, quando analisadas no contexto das provas de avaliações internas no
Brasil, como o caso da Prova Brasil, que será apresentada na próxima seção.

\subsection{Prova Brasil: o foco na leitura}

Segundo Brasil (2013), a Avaliação Nacional do Rendimento Escolar (Anresc), mais conhecida como Prova Brasil, é uma avaliação censitária, criada em 2005 e desenvolvida pelo Instituto Nacional de Estudos e Pesquisas Educacionais Anísio Teixeira (Inep/MEC), que envolve todas as escolas da rede pública de ensino, das zonas urbanas e rurais, que possuam pelo menos 20 estudantes matriculados no 5 o e no 9 o ano do ensino fundamental regular.

Brasil (2013) ainda define que a Prova Brasil é aplicada a cada dois anos e avalia o desempenho dos estudantes em Língua Portuguesa, com foco em leitura, e em Matemática, com ênfase na resolução de problemas. Além disso, fornece informações sobre o contexto extra e intraescolar, associadas ao desempenho. Para elaborar as Matrizes de Referência de Língua Portuguesa e de Matemática da Prova Brasil, o Inep tomou por base os Parâmetros Curriculares Nacionais e outros materiais.

Assim, ainda segundo Brasil (2013), em Língua Portuguesa, no 5a ano, avaliam-se as habilidades de leitura em 22 questões. Entende-se que um bom leitor recorre a seus conhecimentos linguísticos para perceber os sentidos e as intenções de um texto. A Matriz estabelece um conjunto de saberes e de habilidades cujo domínio é esperado de alunos dos anos avaliados. As habilidades são detalhadas na Matriz por meio de descritores, que contemplam os objetivos de ensino de leitura considerados mais relevantes e possíveis de serem avaliados por meio dos testes aplicados, os quais incluem itens de múltipla escolha.

Como já apontado, os PCNs apresentam uma concepção de leitura ou de leitor competente imprecisa, talvez pelos vinte anos que separam 
a sua publicação da sua aplicação nas provas censitárias elaboradas em larga escala e da prática pedagógica diária. A próxima seção apresentará uma perspectiva teórica fundamentada na própria língua: A Semântica Argumentativa.

\section{Semântica Argumentativa: a língua como materialidade}

Segundo Barbisan (2013), a Semântica Argumentativa foi criada na França, na École des Hautes Études en Sciences de Paris por Oswald Ducrot, inicialmente com Jean-Claude Anscombre e, atualmente, por Ducrot com a colaboração de Marion Carel, no mesmo centro de pesquisas francês. Barbisan (2013) relata que o próprio Ducrot afirma que toda sua teoria foi radicalmente influenciada pelos pressupostos saussurianos, já que, ao ler o capítulo sobre valor no Curso de Linguística Geral (CLG), Ducrot reconhece que a realidade linguística é fundamentada não por aquilo que a define positivamente, mas por suas relações de negatividade com as outras unidades do sistema e com o sistema todo.

Bouquet (1997) afirma que a teoria do valor foi esboçada nas aulas de 23, 27 e 30 de junho e 4 de julho de 1911, no terceiro curso, portanto. 0 autor critica a maneira como a teoria do valor foi apresentada no CLG, já que os editores separaram do capítulo sobre o valor linguístico, o capítulo sobre as relações sintagmáticas e as relações paradigmáticas. Segundo Bouquet, Saussure afirma que o valor de um signo só estará completo na intersecção dos dois eixos. O eixo sintagmático, das combinações (in praesentia) que considera não só as relações internas do signo, bem como as relações do signo com aquilo que está ao seu redor, mas, também, o eixo paradigmático, das associações, (in absentia) que trata do signo e suas relações mentais, ou seja, tudo aquilo que pode ser associado a determinado signo. É somente nessa intersecção que Saussure, segundo Bouquet, entende o valor linguístico.
Mesmo diante da crítica apresentada por Bouquet, faz-se necessário voltar ao CLG para compreender toda a complexidade da noção de valor para os fundamentos da ciência linguística, ou da linguística enquanto ciência, já que como apontam Fiorin, Flores e Barbisan (2017, p. 8) “O Curso é, para a Linguística, um discurso fundador." Mas, é preciso ir além e mostrar como o conceito de valor aparece nos próprios manuscritos de Saussure (Escritos de Linguística Geral) e em outras fontes, que chegam aos linguistas via diferentes pesquisadores, já que como aponta Lima (2017, p. 64)

O valor reside no material mais rico da "filosofia" saussuriana, já que barrava a possibilidade de inserir na nova ciência uma formalidade enamorada com uma teoria representacionista da língua - a língua não seria uma simples nomenclatura das coisas do mundo - e sedimentava a concepção de língua como um sistema, cujas "entidades" - lidas aqui como qualquer extrato linguístico - estariam em constante relação.

Na perspectiva saussuriana, o princípio de identidade de uma unidade linguística é marcado pela relação de oposição estabelecida com as outras do sistema linguístico. Saussure (2004, p. 66) deixa claro que “[...] a língua só se alimenta, em sua essência, de oposições, de um conjunto de valores perfeitamente negativos, que só existem por seu contraste mútuo." Para ilustrar seu posicionamento, o linguista compara a língua a uma partida de xadrez, no qual o valor dos elementos é estabelecido na relação com os demais elementos do jogo. Ou seja, para Saussure (2004, p. 30, grifos do autor), "uma forma não significa, mas vale."

Ainda na tentativa de esclarecer a noção de valor para Saussure, a reflexão abaixo evidencia que noção de valor está intimamente relacionada com a noção de sistema, uma vez que é no sistema que as relações se estabelecem, por isso não há valores "prontos", cada termo (para usar a mesma expressão da reflexão saussuriana) que só adquire seu valor situado num sistema, ou seja, em relação com os outros termos desse 
sistema, sendo impossível estudar um termo sem estudar o sistema como um todo.

Valor é, eminentemente, sinônimo, a cada instante, de termo situado em um sistema de termos similares, do mesmo modo que é, eminentemente, sinônimo, a cada instante, de coisa cambiável. [...] Considerar a coisa cambiável, por um lado e, por outro, os termos co-sistemáticos, não revela nenhum parentesco. É próprio do valor relacionar essas duas coisas. Ele as relaciona de um modo que chega a desesperar o espírito pela impossibilidade de se investigar se essas duas faces do valor diferem por ele ou em quê. A única coisa indiscutível é que o valor existente nesses dois eixos é determinado segundo esses dois eixos concomitantemente (SAUSSURE, 2004, p. 289. grifo do autor).

Refletindo sobre a última frase apresentada nesse fragmento, os Escritos de Linguística Geral (2002) trazem uma reflexão saussuriana capaz de validar a crítica de Bouquet (1997) já apresentada acerca da ausência das indicações das relações associativas e das combinações para a explicação sobre o valor linguístico no CLG. A nota incompleta de Saussure aborda o que ela chama de fala efetiva e fala potencial definindo fala efetiva como o sintagma ou a combinação de elementos contidos numa seção de fala real ou, ainda, o regime em que os elementos unem-se ao elemento que vem antes ou depois dele. Já a fala potencial é detalhada como a oposição da fala real, ou a coletividade de elementos concebidos e associados pelo espírito. A reflexão incompleta em que Saussure evidencia a dificuldade em explicar o eixo das relações associativas. "Toda a espécie de elemento vocal (e, como veremos, toda espécie de elementos morfológicos) é sujeito, por natureza, a existir sob dois regimes: aquele em que ele se torna definível com relação ao que segue e precede, aquele em que ele é definível com relação a [ ]".

Assim, entende-se que seja necessário explicitar alguns conceitos fundantes da Semântica Argumentativa fortemente vinculados às reflexões saussurianas, por exemplo, as oposições ducrotianas entre material linguístico/manifestação ou realização linguística, frase/enunciado, sentido/ significação, texto/discurso.

Para o semanticista (1984), material linguístico pode ser compreendido como uma entidade abstrata que não muda nas situações de uso, correspondendo a língua saussuriana. Ou seja, é um constructo teórico que se mantém sempre igual. Esse material possibilita diferentes manifestações ou realizações utilizadas pelo locutor, em um tempo e um espaço específico, sendo, portanto, únicos e irrepetíveis. Ainda, consoante Ducrot (1984, p.369), a noção de realização linguística, correspondente à fala em Saussure, pode ser entendida a partir de três diferentes sentidos: o que é realizado; acontecimento; e processo de produção.

Com base na distinção material linguístico/manifestação ou realização linguística, podem ser entendidos os conceitos de frase/enunciado, texto/discurso. Para Ducrot (1984), a frase representa o material linguístico, o constructo teórico utilizado pelo locutor. Já o conceito de enunciado corresponde ao que foi de fato realizado, quer no âmbito oral, quer no escrito. Ao opor frase e enunciado, Ducrot distingue os conceitos de significação e sentido. Para o autor, significação representa o valor semântico da frase, e sentido, o valor semântico do enunciado. Também pertencente ao domínio das entidades abstratas está o conceito de texto, concebido pelo autor como uma sequência de frases. Assim, tanto frase quanto texto encontram-se no âmbito das entidades abstratas, não observáveis.

Por sua vez, discurso é entendido como uma sequência de enunciados interligados. Com efeito, enunciado e discurso podem ser compreendidos como construções concretas, observáveis. Dito de outro modo: texto está para frase, assim como discurso para enunciado. Retomando os três sentidos atribuídos à realização linguística, é possível entender que o primeiro sentido corresponde ao que é realizado, isto é, ao enunciado e ao discurso. 0 segundo sentido representa a enunciação, ou seja, o acontecimento histórico, no qual 
a frase torna-se objeto do enunciado ou do discurso. Já o terceiro sentido de realização, para Ducrot, pode ser compreendido como o processo de produção do enunciado ou do discurso, denominado de atividade linguística.

Consoante o autor (1984, p. 369), a realização linguística ocorre em dois níveis: o elementar e o complexo. Ambos são formados por uma entidade concreta e uma abstrata, uma vez que, para Ducrot, é a partir do observável, isto é, da produção dos falantes que se chega à entidade abstrata. Do que foi pontuado até aqui, sintetiza-se:

a) nível elementar: do enunciado (entidade concreta) chega-se à frase (entidade abstrata);

b) nível complexo: do discurso (entidade concreta) abstrai-se o texto (entidade abstrata).

Por certo, Azevedo (2006, p. 61. grifo do autor) relaciona os pressupostos de Ducrot ao pensamento saussuriano, ao explicitar que:

[...] a dicotomia metodológica langue/parole está intimamente relacionada à oposição frase/enunciado: parte-se da parole, do enunciado, para descrever a langue, a frase; a langue subjaz à parole, o que equivale dizer, em termos ducrotianos, a frase está subjacente ao enunciado.

Após explicitar, minimamente, algumas concepções norteadoras da Semântica Argumentativa, prossegue-se apresentando os postulados ducrotinianos e o percurso do semanticista para manter-se fiel aos postulados saussurianos.

\subsection{Teoria da Argumentação na Língua: a busca pelo imanentismo}

A Teoria da Argumentação na Língua (ADL) é uma teoria que sofreu várias reformulações para manter-se fiel a dois importantes e interligados conceitos. Na sequência, apresentar-se-á um breve panorama de cada uma das fases da ADL.
A forma standard (1983), primeira fase da teoria, desenvolvida por Ducrot e Anscombre, segundo Barbisan (2002), pretende mostrar que o potencial argumentativo é o conjunto de enunciados que podem servir de conclusão e depende da continuação discursiva de enunciados-conclusões diversos. Os autores rejeitam tais princípios pois percebem que partindo de operadores como pouco e um pouco se chegavam às mesmas conclusões, por meio de trajetos argumentativos diferentes.

Barbisan (2002) mostra que a noção de topos transforma a forma standard e, juntamente à noção de polifonia, introduz a forma recente (1988), desenvolvida por Ducrot e Anscombre. Segundo Barbisan, a nova versão teórica se fundamenta em duas condições: a primeira é a de que um argumento deve justificar uma determinada conclusão; e a segunda indica que o trajeto do argumento à conclusão se faz mediante um princípio argumentativo: o topos. Esse apresenta, por sua vez, três características: é comum, porque é compartilhado, aceito por uma coletividade; é geral, na medida em que o princípio convocado é válido, não só na situação de que se fala, mas em outras situações análogas; é gradual, porque põe em relação duas propriedades, duas escalas. Essa fase também foi rejeitada após a constatação de que o topos não era linguístico, mas uma "máxima" extralinguística, e tal fundamento contrariava os princípios basilares da Semântica Argumentativa que serão apresentados e discutidos na sequência. Ainda na forma recente, Ducrot apresenta a noção de polifonia, que será a base teórica adotada para as análises desenvolvidas no próximo tópico. Tal opção teórica/metodológica exige uma revisão mais aprofundada de seus postulados por isso será apresentada na próxima seção.

Atualmente, Oswald Ducrot e Marion Carel (1992) trabalham e desenvolvem a Teoria dos Blocos Semânticos, em que novos conceitos da teoria são apresentados na busca de aprofundar a explicação do valor na 
linguagem (BARBISAN, 2013). Nessa fase, entende-se que só o discurso é doador de sentido e, por sua vez, os discursos são os encadeamentos argumentativos, as sequências de duas proposições (no sentido sintático do termo) ligadas por um conector, que pode ser do tipo donc (portanto) ou do tipo pourtant (no entanto) (BARBISAN, 2002). Ducrot (2005 apud AZEVEDO, 2012, p. 168, grifo do autor)

[...] em Saussure, a noção de relação de um signo com outros é relativamente vaga, sendo esse o motivo de a TAL propor como relações semanticamente pertinentes as argumentativas, nos parâmetros da TBS, os encadeamentos argumentativos em donc e em pourtant entre um signo e outro. Dito de outro modo, para a TAL, os encadeamentos em donc ou em pourtant possíveis de serem produzidos depois de um signo ter sido enunciado constituem sua significação.

Assim, a primeira máxima defendida pelos teóricos da Semântica Argumentativa ao longo de seu desenvolvimento é a de que a argumentação está inscrita no próprio sistema linguístico. A segunda, interligada à primeira, é a de que estando a argumentação inscrita no sistema linguístico, não é necessário recorrer ao extralinguístico para explicar os discursos. Posição já apresentada por Gomes (2016, p. 66) “[...] uma teoria da argumentação essencialmente linguística, que procura descrever o sentido dos enunciados pela língua, sem apelar para estratégias extralinguísticas [...]".

Ducrot e Carel (2008, p. 9) esclarecem a concepção de argumentação que assumem como "[...] uma sequência de dois enunciados ligados por um conector [...]" evidenciando a fidelidade aos pressupostos saussurianos de valor, já que o significado de cada enunciado não está pronto, mas se constitui na relação que se estabelece entre esses e entre os enunciados e o conector. Barbisan (2012, p. 136) nesse contexto afirma que "[...] o enunciado define-se pelas possibilidades de resposta que abre e por aquelas que fecha, e, desse modo, a realidade do enunciado não está nele, mas fora dele, nos enunciados que o continuam, e que a língua oferece ou proíbe a quem dela faz uso."

Quanto à definição do objeto de estudo de Ducrot, mas se mantendo radicalmente fiel à noção de valor de Saussure, Barbisan (2017, p. 167-168, grifos do autor) afirma que "[...] Ducrot escolhe estudar a relação entre significados (conceitos) [...] o que lhe permite construir uma teoria semântica que toma como objeto de estudo a língua, na qual vê o valor expresso pelas relações sintagmáticas, in praesentia, por meio de encadeamentos denominados argumentações." Assim, Ducrot opta por estudar o sentido (valor semântico do enunciado) partindo do enunciado, do discurso, das relações estabelecidas apenas no e pelo sistema linguístico.

Na próxima seção, o foco será apresentar o Teoria da Polifonia, base teórica selecionada para as análises do corpus.

\subsection{Teoria Polifônica: as diferentes vozes na construção dos sentidos}

A Teoria da Polifonia, desenvolvida por Ducrot e fundamentada nas obras O Dizer e o dito (1987) e Polifonia y argumentación (1990), tem como pressuposto basilar o de que existem num mesmo enunciado vários sujeitos com estatutos linguísticos diferentes: o sujeito empírico (SE), o locutor (L) e o enunciador (E).

Pela noção de polifonia, na forma recente, a argumentação é descrita por meio de enunciadores que se apresentam no enunciado. Assim, Ducrot $(1987,1988$ apud BARBISAN, 2006) “[...] defende que um enunciado comporta não apenas um sujeito falante, mas vários [...]". O sentido, assim, é polifônico, isto é, nasce da confrontação de diferentes funções. Personagens que o autor de um enunciado põe em cena, a saber: o sujeito empírico (SE), o produtor efetivo do enunciado, que não interessa aos estudos do linguista 
semanticista; o locutor (L), responsável pela produção do enunciado; o enunciador (E), pontos de vista abstratos que o locutor, ao se enunciar, traz para o seu discurso (BARBISAN, 2002).

Consoante Ducrot (1990), na polifonia linguística, o conteúdo pressuposto está inscrito na significação; e o locutor $(L)$ pode tomar diferentes atitudes em relação aos pontos de vista mobilizados: identificar-se com um dos enunciadores ( $E$ ), assumindo seu ponto de vista; concordar com um dos enunciadores (E), aceitando o ponto de vista; ou opor-se a um enunciador (E), recusando-lhe o ponto de vista.

Desse modo, Azevedo (2016, p. 78, grifo da autora) esclarece:

Descrever o sentido de um enunciado por essa versão da TP demanda, então, verificar: se o enunciado contém a função locutor (o que não acontece, segundo Ducrot (1990:19), com os provérbios, por exemplo); quais são os enunciadores atualizados por L no enunciado; e que atitude é adotada por L em relação ao ponto de vista de cada enunciador mobilizado.

Assim, para Ducrot (1990) o L (locutor) é o responsável pelo enunciado, marcado no enunciado pelas inscrições de primeira pessoa (eu, me, mim) e de tempo e espaço da enunciação (aqui, agora) podendo ser totalmente diferente do SE (sujeito empírico), uma vez que em enunciados do tipo Como eu sou inteligente (AZEVEDO, 2015) diante de alguém que cometeu um erro, o eu do enunciado não representa o SE (sujeito empírico) que atualizou $o$ discurso, mas, sim, aquele a quem o SE (sujeito empírico) se refere, que cometeu o erro, e que é o L (locutor) responsável pelo enunciado totalmente diferente do SE (sujeito empírico). Tal distinção (L(locutor)/SE (sujeito empírico), segundo o autor, ainda é importante porque permite dar "voz" a seres incapazes de falar como no lembrete aos donos de animais de estimação, em que aparece um cachorro junto ao discurso Recolhe a minha caca, vai? O "minha" remete ao cachorro, que não é o SE (sujeito empírico), mas representa o L(locutor), que lembra aos donos de cachorros que devem juntar as fezes deles.

Quanto à terceira figura de discurso apresentada por Ducrot, o E (enunciador), o autor admite que "[...] todo enunciado apresenta um certo número de pontos de vista relativos às situações de que o enunciado fala [...]" (DUCROT, 1990, p. 19). Assim, os enunciadores (pontos de perspectiva abstratos) representam as origens dos diferentes pontos de vista que se apresentam no enunciado. O L (locutor) poderá se identificar ou não com alguns E (enunciadores). Azevedo (2015) afirma que o L (locutor) pode adotar três atitudes em relação a cada E (enunciador) mobilizado em cada enunciado (aceitar, recusar, assumir). Segundo a autora, o L (locutor) aceita um E (enunciador) como no caso da pressuposição ${ }^{1}$. Por exemplo no enunciado "Maria chegou em casa", o L (locutor) aceita que o pressuposto de Maria não estava em casa e agora está. O L (locutor) recusa um E (enunciador) em discursos como "Maria não chegou em casa" quando um E (enunciador) afirma a chegada de Maria e outro nega. Logo, o primeiro é recusado pelo L (locutor) enquanto o segundo é assumido por ele.

Sob esse viés, apresentar-se-á uma proposta de compreensão leitora fundamentada nos pressupostos da Teoria da Polifonia, com a intenção de contribuir efetivamente com o desenvolvimento dessas habilidades.

1 [...] o pressuposto é o que apresento como pertencendo ao domínio comum das duas personagens do diálogo, como o objeto de uma cumplicidade fundamental que liga entre si os participantes do ato de comunicação. Em relação ao sistema dos pronomes poder-se-ia dizer que o pressuposto é apresentado como pertencendo ao "nós", [...] Ou, ainda, se as imagens temporais forem preferidas, é possível dizer como pertencendo ao "nós", [...] Ou, ainda, se as imagens temporais forem preferidas, é possível dizer que [...] o pressuposto, mesmo que, de fato, nunca tenha sido introduzido anteriormente ao ato de enunciação (como se o ouvinte não soubesse, antes da formulação do enunciado (3), que Jacques fictício, ao qual o locutor parece referir-se (DUCROT p. 20). 


\section{Proposta de compreensão leitora via Teoria Polifônica da Enunciação: a compreensão via material linguístico}

Antes de apresentar-se esta proposta, cabe relembrar dos diferentes usos catastróficos que já se materializaram, quando teorias linguísticas foram aplicadas em sala de aula sem a devida transposição didática. Hanel (2010) já afirma as potencialidades da Semântica Argumentativa para o ensino, como também pretende-se mostrar aqui, mas cabe trazer Azevedo (2016), para alertar que o aluno, usuário de língua, faz da língua um instrumento para conferir sentido às suas interações verbais em sociedade $\mathrm{e}$ não um objeto de estudo, como é o caso do linguista, que descreve e explica o sistema linguístico sob diferentes perspectivas. Assim, é preciso que o trabalho com o texto, como será aqui apresentado, dê conta de capacitar o aluno a compreender o texto para melhor interagir socialmente e não o tratando como um linguista.

Azevedo, em relação à atividade de leitura, afirma

[...] a constituição de sentido é composta por três níveis ordenada e hierarquicamente dispostos, assim, sem que o primeiro seja concluído, não há como passar ao segundo e assim sucessivamente. São eles: (1) decodificação, a decifração do código escrito, o reconhecimento e a combinação de letras em palavras e enunciados; (2) compreensão, a constituição, de modo analítico e sintético, do sentido das inter-relações das unidades de composição do discurso e do discurso como uma totalidade semântico-enunciativa; (3) interpretação, o estabelecimento de relações entre o conteúdo temático do discurso e os contextos de produção e de recepção desse discurso (2016, p. 75, grifo da autora).

Aceitando essa descrição, é importante mostrar que a análise proposta na sequência fica circunscrita aos níveis 1 e 2 , já que esses podem ser realizados via materialidade linguística, enquanto o terceiro não.
A questão abaixo (Figura 1) foi retirada do Simulado da Prova Brasil 2011 disponível na página do MEC.

Figura 1 - Discurso da Prova Brasil 2011

\section{AVASSOURA}

A vassoura de uma bruxa é uma das mais importantes pocas de seu equipamento. Pode ser utilizada em casa, mas também constitui um meio de transporte muito barato.

\section{COMO PREPARAR SUAVASSOURA MÁGICA}
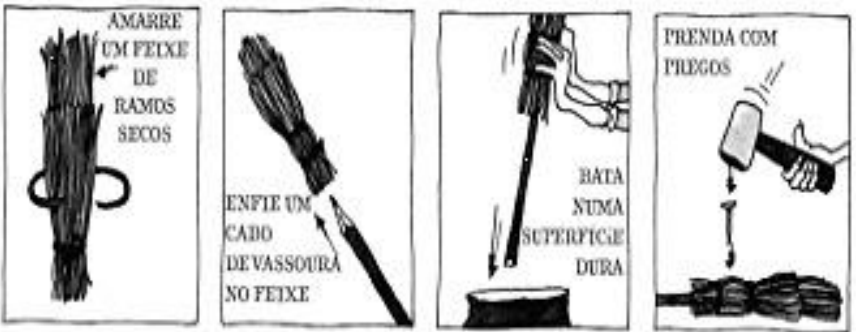

COMOVOAR EM SUA VASSOURA
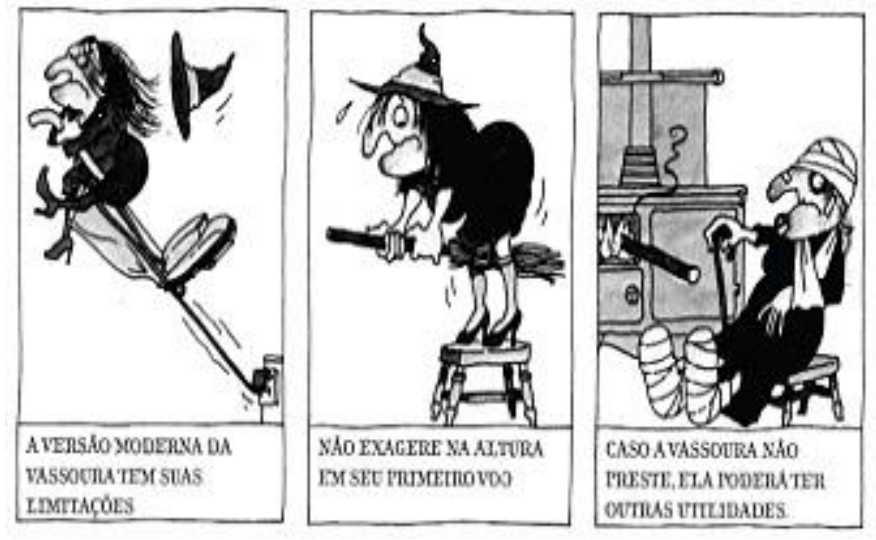

Fonte: Prova Brasil 2011 
As questões propostas foram as seguintes:

01 IT_026026

No texto, uma PASSAGEM ENGRAÇADA é

(A) "Amarre um feixe de ramos secos."

(B) "A versão moderna da vassoura tem suas limitações."

(C) "Bata numa superfície dura."

(D) "Enfie o cabo da vassoura no feixe."

Essa questão contempla o D 13 Identificar efeitos de ironia ou humor em textos variados.

02 IT_025878

No trecho "Caso a vassoura não preste, ela poderá ter outras utilidades.", a palavra sublinhada refere-se à
(A) altura do voo.
(B) bengala da bruxa.
(C) bruxa machucada.
(D) vassoura mágica.

Essa questão contempla o D 2 Estabelecer relações entre partes de um texto, identificando repetições ou substituições que contribuem para a continuidade de um texto.

03 IT_026030

O texto é divertido, PRINCIPALMENTE, porque

(A) apresenta uma bruxa trapalhona e medrosa.

(B) dá instruções sobre como fabricar uma vassoura.

(C) ensina como a bruxa deve limpar a sua casa.

(D) trata de como fazer uma vassoura e usá-la no fogão.

Essa questão contempla o D 5 Interpretar texto com auxílio de material gráfico diverso (propagandas, quadrinhos, foto, etc.).

Em uma análise bastante superficial, devido ao espaço aqui disponível, é possível afirmar que as questões propostas contemplam os descritores indicados somente sob uma ótica "forçada", além disso, as respostas para as questões não estão no discurso, dependendo de uma série de vivências do leitor que não podem ser mensuradas em uma prova em larga escala. Observando-se a primeira questão proposta pode-se perceber que o aluno deve identificar uma "passagem engraçada". Ora, o aluno pode ter se identificado com outra alternativa que, para ele produz graça, ou não verificar nenhuma passagem engraçada. Já a segunda questão proposta apresenta um problema quanto às alternativas de respostas, pois, ao se considerar o fragmento destacado "Caso a vassoura não preste, ela poderá ter outras utilidades.", a resposta correta não está nas alternativas apresentadas, já que o pronome "ela" nesse fragmento, retoma apenas o termo vassoura e a resposta indicada como correta é "a vassoura mágica". Já a última questão solicita que o aluno identifique o principal elemento que torna o texto divertido, novamente, muitas questões extralinguísticas podem ser consideradas pelo aluno para responder essa questão.

A proposta de compreensão leitora, via teoria polifônica, considera apenas o discurso "A vassoura de uma bruxa é uma das mais importantes peças de seu equipamento. Pode ser utilizada em casa, mas também constitui um meio de transporte muito barato.", uma vez que a teoria escolhida para subsidiar a análise é uma teoria linguística, assim a parte imagética do discurso não está sendo considerada agora. Não que não se possa trabalhar com o discurso todo, mas seria necessário outro aporte teórico para dar conta desse fragmento do discurso (as imagens).

Para que o aluno, efetivamente, aprenda a ler, é necessário a intervenção pedagógica do professor, como descrito nos PCNs e já assinalado neste artigo, por isso, a teoria polifônica da enunciação permite identificar o jogo polifônico presente no discurso, mas o aluno só irá perceber tal jogo polifônico, constituído da presença dos diferentes enunciadores, no momento em que o professor permitir o contato dos alunos com tais pontos de vista do texto. Assim, questionamentos do professor como os presentes no Quadro 1. 
Quadro 1 - Quadro polifônico

\begin{tabular}{|c|c|c|c|}
\hline Enunciado & Enunciadores & Posição do locutor (L) & Questões \\
\hline $\begin{array}{l}\mathrm{E}_{1}: \text { a vassoura da bruxa é uma das mais } \\
\text { importantes peças de seu equipamento }\end{array}$ & $\begin{array}{l}\mathrm{E}_{1}: \text { há uma vassoura } \\
\mathrm{E}_{2}: \text { a vassoura é da bruxa } \\
\mathrm{E}_{3}: \text { há um equipamento } \\
\mathrm{E}_{4}: \text { o equipamento é da bruxa } \\
\mathrm{E}_{5}: \text { o equipamento tem peças } \\
\mathrm{E}_{6}: \text { o equipamento tem peças importantes } \\
\mathrm{E}_{7}: \text { a vassoura da bruxa é uma peça do } \\
\text { equipamento } \\
\mathrm{E}_{8}: \text { a vassoura da bruxa é uma peça } \\
\text { importante do equipamento } \\
\mathrm{E}_{9}: \text { a vassoura da bruxa é uma peça muito } \\
\text { importante do equipamento }\end{array}$ & $\begin{array}{l}\text { O locutor aceita } \mathrm{E}_{1,} \mathrm{E}_{2,} \mathrm{E}_{3}, \mathrm{E}_{4}, \mathrm{E}_{5}, \mathrm{E}_{6}, \mathrm{E}_{7 \mathrm{e}} \mathrm{E}_{8} \text {. } \\
\text { O locutor assume } \mathrm{E}_{9} \text {. }\end{array}$ & $\begin{array}{l}\text { De quem é a vassoura? } \\
\text { A vassoura da bruxa é uma peça qualquer? } \\
\text { A vassoura da bruxa faz parte de um conjunto maior? } \\
\text { Que palavra evidencia que o equipamento da bruxa tem } \\
\text { outras coisas? } \\
\text { A vassoura da bruxa é apenas importante no conjunto das } \\
\text { peças do equipamento? }\end{array}$ \\
\hline $\begin{array}{l}E_{2} \text { : a vassoura da bruxa pode ser utilizada } \\
\text { em casa }\end{array}$ & $\begin{array}{l}\mathrm{E}_{1}: \text { há uma vassoura } \\
\mathrm{E}_{2}: \text { a vassoura é da bruxa } \\
\mathrm{E}_{3}: \text { a vassoura da bruxa pode ser utilizada } \\
\text { para o serviço doméstico }\end{array}$ & $\begin{array}{l}\text { O locutor aceita } E_{1} \text { e } E_{2} \text {; } \\
\text { O locutor assume } E_{3} \text {. }\end{array}$ & Como a vassoura da bruxa pode ser utilizada? \\
\hline $\begin{array}{l}\mathrm{E}_{3}: \text { a vassoura da bruxa constitui um meio } \\
\text { de transporte muito barato }\end{array}$ & $\begin{array}{l}\mathrm{E}_{1}: \text { há uma vassoura } \\
\mathrm{E}_{2}: \text { a vassoura é da bruxa } \\
\mathrm{E}_{3}: \text { a vassoura da bruxa é um meio de } \\
\text { transporte } \\
\mathrm{E}_{4}: \text { a vassoura da bruxa é um meio de } \\
\quad \text { transporte barato } \\
\mathrm{E}_{5}: \text { a vassoura da bruxa é um meio de } \\
\text { transporte muito barato }\end{array}$ & $\begin{array}{l}\text { O locutor aceita } E_{1,} E_{2}, E_{3} \text { e } E_{4} \text {. } \\
\text { O locutor assume } E_{5} \text {. }\end{array}$ & $\begin{array}{l}\text { Além do serviço doméstico, a vassoura da bruxa tem outra } \\
\text { finalidade? } \\
\text { A vassoura da bruxa constitui apenas um meio de transporte? } \\
\text { O que a palavra (articulador) mas indica neste discurso? }\end{array}$ \\
\hline
\end{tabular}

Tais questões levam os alunos a identificar os diferentes enunciadores (E) presentes nos enunciados, mas, principalmente, compreender aqueles efetivamente assumidos no discurso. Após um trabalho pedagógico com esse propósito, seria possível ao professor elaborar uma questão como a apresentada na sequência.

O discurso "A vassoura de uma bruxa é uma das mais importantes peças de seu equipamento. Pode ser utilizada em casa, mas também constitui um meio de transporte muito barato." traz uma série de afirmações. Assinale apenas a alternativa que mostra o ponto de vista assumido pelo locutor do discurso. a) O equipamento da bruxa tem outras peças.

b) A vassoura da bruxa pode ser utilizada em casa e constitui um meio de transporte muito barato.

c) A vassoura da bruxa pode ser utilizada.

d) A bruxa tem um equipamento.

O aluno, para responder a essa questão, deverá perceber que todas as alternativas explicitadas são pontos de vista aceitos no discurso, mas apenas a alternativa B apresenta o ponto de vista assumido pelo locutor do discurso. É possível que uma proposta de transposição didática da Teoria 
Polifônica ainda exija muitas reflexões teórico-metodológicas, mais eis que se apresenta possível.

\section{Considerações finais}

As considerações aqui apresentadas são formuladas mais como desafios futuros do que como pontos finais. Inicialmente, é preciso repensar teóricometodologicamente alguns conceitos apresentados nos PCNs devido às suas imprecisões. Também, torna-se necessário rever o que realmente aparece como objeto de avaliação nas provas censitárias, buscando garantir que todos os alunos respondam às provas com as mesmas condições. Assim, centrando a prova na materialidade linguística, parece possível equiparar todos os alunos, independentemente das suas experiências de vida, seus conhecimentos sobre os autores, etc.

Quanto à Teoria Polifônica, espera-se ter contribuído para desvendar tão rico enigma que se apresenta aos semanticistas, mostrando o potencial que a teoria apresenta para a compreensão leitora, espera-se provocar o interesse e a pesquisa científica de linguistas para aperfeiçoar essa proposta e apresentar outras propostas vinculadas a diferentes áreas do ensino.

\section{Referências}

AZEVEDO, T. M. Encadeamentos argumentativos, relações sintagmáticas e associativas; reflexões sobre o ensino de leitura. Antares, Caxias do Sul, v. 8, n. 15, p. 48-65, jan./jun. $2016 \mathrm{a}$

AZEVEDO, T. M. Polifonia linguística: uma proposta de transposição didática para o ensino da leitura. Letras de Hoje, Porto Alegre, v. 51, n. 1, p. 73-81, jan./mar. 2016b.

AZEVEDO, T. M. Em busca do sentido do discurso: a semântica argumentativa como uma possibilidade para a descrição do sentido do discurso. Caxias do Sul: EDUCS, 2006.
AZEVEDO, T. M. Pontos de vista Outro(s): polifonia e alteridade. Desenredo, Passo Fundo, v. 11 , n. 2, p. 439-455, jul.-dez. 2015

AZEVEDO, T. M. Semântica argumentativa: a Teoria e seu potencial para a pesquisa e para o ensino. In: DI FANTI, M. da G.; BARBISAN, L. B. Enunciação e Discurso. São Paulo: Contexto, 2012.

BARBISAN, L. B. O sentido no discurso: o olhar da Teoria da Argumentação na Língua. In: DI FANTI, M. da G.; BARBISAN, L. B. Enunciação e Discurso. São Paulo: Contexto, 2012.

BARBISAN, L. B. Do signo ao discurso: a complexa natureza da linguagem. In: FIORIN, J. L.; FLORES, V. N.; BARBISAN, L. B. (Org.). Saussure: a invenção da linguística. São Paulo: Contexto, 2017.

BARBISAN, L. A construção da argumentação no texto. Letras de Hoje, Porto Alegre, v. 37 n. 3, p. 135-147, set. 2002 .

BARBISAN, L. Semântica Argumentativa. In: FERRAREZI JUNIOR, C.; BASSO, R. Semântica, semânticas: uma introdução. São Paulo: Contexto, 2013.

BOUQUET, S. Introdução à Leitura de Saussure. São Paulo: Cultrix, 1997.

BRASIL. Secretaria de Educação Fundamental. Parâmetros curriculares nacionais: língua portuguesa. Brasília: [s.n.], 1997.

BRASIL. Ministério da Educação. Prova Brasil. Brasília: [s.n.], 2013. Disponível em: <http://portal.mec.gov.br/prova-brasil>. Acesso em: 22 jul. 2017.

DUCROT, O. O dizer e o dito. Campinas, SP: Pontes, 1987.

DUCROT, O. Polifonia y argumentacion: Conferencias del seminario Teoría de la Argumentación y Análisis del Discurso, Cali: Feriva, 1990.

DUCROT, O. Enunciação. In: Enciclopedia EINAUDI: Linguagem-Enunciação. Lisboa: Imprensa Nacional-Casa da Moeda, 1984.

DUCROT, O.; CAREL, M. Descrição argumentativa e descrição polifônica: o caso da negação. Letras de Hoje, Porto Alegre, v. 43, n. 1, p. 7-18, jan.-mar. 2008.

FIORIN, J. L.; FLORES, V. N. ; BARBISAN, L. B. (Org.). Saussure: a invenção da linguística. São Paulo: Contexto, 2017.

GOMES, N. M. T. Argumentação linguística, enunciação e polifonia. Letras de Hoje, Porto Alegre, v. 51, n. 1, p. 65-72, jan.-mar. 2016. 
HANEL, A. I. Avaliação de propostas de produção de textos dissertativo-argumentativos à luz da teoria da argumentação da língua. 2010. 139f. Dissertação (Mestrado em Letras) - Universidade de Passo Fundo, 2010. Disponível em: <https://secure.upf.br/ pdf/2010AndreiaInesHanel.pdf>. Acesso em: 22 jul. 2010.

LIMA, H. O Curso de Linguística Geral e os manuscritos saussurianos: unde exoriar? In: FIORIN, J. L.; FLORES, V. N.; BARBISAN, L. B. (Org.). Saussure: a invenção da linguística. São Paulo: Contexto, 2017.

SAUSSURE, F. Curso de Linguística Geral. 27. ed. São Paulo: Cultrix, 2006.

SAUSSURE, F. Escritos de Linguística Geral. São Paulo: Cultrix, 2002.

TEIXEIRA. M. É possível a leitura? Revista Nonada, UniRitter, Porto Alegre, ano 8, n. 8, p. 195-204, 2005.

Recebido: $15 / 09 / 201$

Aceito: $30 / 12 / 2017$ 